\title{
Первый опыт лапароскопического выделения желудочно-сальниковой артерии при полной аутоартериальной реваскуляризации миокарда
}

\author{
Габриелян А. В., Сидюк А. В., Мазур А. П., Доманский Т. Н., Береговой О. В., Белейович В. В., \\ Миронюк А. И., Романова С. В., Кудлай И. В., Хавин И. Г., Савенко Г. Ю. \\ ГУ «Национальный институт хирургии и трансплантологии им. А. А. Шалимова НАМН Украины», г. Киев, Украина
}

\begin{abstract}
Резюме. Лапароскопическое выделение правой желудочно-сальниковой артерии (ПЖСА) позволяет значительно снизить риски развития осложнений, связанных с лапаротомией, и расширить возможности ее использования в качестве аутоартериального графта при коронарном шунтировании.
\end{abstract}

Цель. Представить первый опыт использования лапароскопически выделенной ПЖСА в качестве графта при полном аутоартериальном шунтировании.

Материалы и методы. Выполнено 5 операций коронарного шунтирования на работающем сердце с использованием аутоартериальных шунтов.

Результаты. В ранний послеоперационный период ни у одного пациента не было зафиксировано сердечнососудистых событий. Осложнений со стороны желудочно-кишечного тракта не отмечено. При сравнении показателей пациентов, которым выполнялась полная аутоартериальная реваскуляризация с использованием ПЖСА, с данными пациентов, оперированных по традиционной методике, достоверных различий не обнаружено.

Выводы. Первый опыт применения лапароскопически выделенной ПЖСА в качестве артериального кондуита для шунтирования коронарных артерий показал положительные результаты. Применение современной лапароскопической техники делает возможным безопасное и менее травматичное выделение ПЖСА.

Ключевые слова: сальниковая артерия, коронарное шунтирование, ишемическая болезнь сердиа.

Вступление. Одним из главных вопросов коронарной хирургии на сегодняшний день является поиск оптимального графта для коронарного шунтирования. Применение левой внутренней грудной артерии в ка-

честве кондуита давно считается «золотым стандартом» во всем мире. В настоящее время при операциях коронарного шунтирования все чаще применяются обе внутренние грудные (маммарные) артерии как наиболее жизнеспособные и имеющие ряд преимуществ. Многочисленные исследования показывают, что спустя 10 лет $90 \%$ аутоартериальных шунтов остаются проходимыми и функционируют нормально, в то время как 10-летняя проходимость венозных шунтов не превышает $50 \%$ [1].

Несмотря на общую оптимистическую оценку результатов аутоартериального коронарного шунтирования, эта методика имеет ряд нерешенных вопросов: проблема эффективной реваскуляризации аутоартериальными трансплантатами заднедиафрагмальной области миокарда и правой коронарной артерии [2]; использование конструкций Т- и Ү-образных графтов ставит кровоснабжение сердца в зависимость от функционирования одной маммарной артерии; наличие мультифокального атеросклероза с поражением брахиоцефальных артерий делает невозможным приме- нение маммарных артерий для коронарного шунтирования; при использовании обеих внутренних грудных артерий повышается риск развития осложнений со стороны грудины (нестабильность, инфицирование) в послеоперационный период.

Энтузиазм, возникший в 1990-х годах вокруг использования в качестве кондуита лучевой артерии (a. radialis), в настоящее, исчерпал себя.

При использовании лучевой артерии в качестве кондуита частота ее дисфункции в отдаленный период (от 1 года до 5 лет) составляет 26,4\%, аутовенозных шунтов - 24,8 \%. Кумулятивная пятилетняя проходимость шунтов из лучевой артерии после операции аортокоронарного шунтирования составляет 73,6 \%, а аутовенозных шунтов - 75,2 \%. Учитывая отсутствие достоверных преимуществ лучевой артерии над аутовеной, применение ее в качестве кондуита в настоящее время ограничено. Также на частоту дисфункции шунтов из лучевой артерии влияет наличие у пациентов осложненных форм ишемической болезни сердца (ИБС), мультифокального атеросклероза, сахарного диабета и гиперхолестеринемии [3].

Все это требует поиска других графтов. Одним из решений является использование правой желудочносальниковой артерии (ПЖСА). 
Впервые применил ПЖСА для реваскуляризации задней стенки левого желудочка в 1965 году Charles P. Bailey в соответствии с методикой Vineberg A. В 1973 году Sterling Edwards применил данную артерию в качестве шунта для правой коронарной артерии.

Одновременное использование ПЖСА с обеими внутренними грудными артериями приводит к низкой смертности и низкой частоте инфаркта миокарда и повторных вмешательств. По данным исследования Bergsma, et al. [4], в течение 7 лет после операции стенокардия развилась только у 14,6 \% пациентов.

Реваскуляризация миокарда у молодых пациентов с трехсосудистым поражением с использованием правой и левой внутренней грудной артерии, а также ПСЖА обеспечивает отличную 9-летнюю выживаемость пациентов, лучшую с точки зрения отсутствия стенокардии и любых сердечных событий [5].

Результаты 20-летнего наблюдения пациентов, которым было проведено коронарное шунтирование ПЖСА [6], показали, что коэффициент проходимости составлял 97 \% в течение 1 послеоперационного года.

Однако использование ПЖСА при коронарном шунтировании не получило широкого распространения. К причинам, ограничивающим хирургов от использования ПЖСА, можно отнести следующие: технически более сложное выделение; необходимость внедрения еще в одну полость; увеличение длительности операции; отсутствие четкого общепринятого клинического руководства по использованию данного кондуита; сложившиеся стереотипы.

С развитием миниинвазивных хирургических методик появилась возможность лапароскопического выделения ПЖСА. Это позволило значительно снизить риски развития осложнений, связаных с лапаротомией.

Показаниями к использованию ПЖСА для коронарного шунтирования являются планирование множественной аутоартериальной реваскуляризации, повышенный риск использования второй внутренней грудной артерии, сопряженный с несостоятельностью грудины у пациентов с хронической обструктивной болезнью легких, у женщин с сахарным диабетом, больных с ожирением, нехватка венозных и артериальных кондуитов для множественного шунтирования.

K преимуществам использования аутоартериальных шунтов из ПЖСА относится подходящая локализация для шунтирования нижней стенки сердца in situ (без наложения дополнительного анастомоза).

Противопоказаниями к использованию ПЖСА являются перенесенная или планируемая операция в брюшной полости, ранее выполненная радиотерапия в абдоминальной области, язвенная болезнь желудка, ожидаемая короткая продолжительность жизни или преклонный возраст, почечная недостаточность, тяжелые периферические сосудистые заболевания или признаки тяжелой органной ишемии, экстренная операция у гемодинамически нестабильных пациентов, гемодинамически значимое сужение чревного ствола по результатам предоперационной целиакографии, малая длина или недостаточный диаметр ПЖСА во время интраоперационной ревизии.

В данной статье представлен наш первый опыт лапароскопического выделения ПЖСА в качестве графта при полном аутоартериальном шунтировании.

Материалы и методы. В отделении хирургии и трансплантации сердца ДУ «НИХТ им. А. А. Шалимова НАМН Украины» было проведено 5 операций коронарного шунтирования с использованием аутоартериальных шунтов - двух внутренних грудных и правой желудочносальниковой артерий. Все пациенты были мужчинами, средний возраст которых составлял $51 \pm 8$ лет, имели II-III класс стенокардии, многососудистое поражение коронарных артерий. Всем была показана операция коронарного шунтирования.

Ход операции: параллельно со стандартным выделением левой и правой внутренних грудных артерий, лапароскопически выделялась ПЖСА (a. gastroepiploica dextra) с использованием аппарата Ligasure. После клипирования и отсечения дистального конца артерия проводилась в полость перикарда через сформированное отверстие в диафрагме. С помощью левой внутренней грудной артерии шунтировались ветви огибающей артерии, правая внутренняя грудная артерия анастомозировалась с передней межжелудочковой ветвью левой коронарной артерии. У 4 пациентов ПЖСА использовалась для шунтирования задней межжелудочковой ветви, у 1 пациента - для шунтирования правой коронарной артерии. Все операции были выполнены по методике off-pump. Все анастомозы выполнялись стандартно с использованием вакуумных стабилизаторов сердца.

Результаты и обсуждение. В ранний послеоперационный период ни у одного пациента не было зафиксировано сердечно-сосудистых событий, таких как периоперационный инфаркт миокарда, острое нарушение мозгового кровообращения, а также нарушений ритма. Данные пациенты в послеоперационный период не требовали инотропной поддержки, а также дополнительной аналгезии. Осложнений со стороны желудочно-кишечного тракта в виде гастростаза, нарушения стула, рвоты не отмечено. Среднее время нахождения пациентов на искусственной вентиляции легких после операции составило $3,0 \pm 1,0$ часа. Среднее время пребывания пациентов в отделении интенсивной терапии $-30,2 \pm 8,4$ часа. Средний постоперационный период $-8,0 \pm 1,5$ дня.

При сравнении показателей пациентов, которым выполнялась полная аутоартериальная реваскуляризация с использованием ПЖСА, с данными пациентов, оперированных по традиционной методике (LIMA- 
LAD, остальные артерии шунтируются венами), достоверных различий не обнаружено.

Среднесрочные результаты наблюдения (3,0 \pm 1,2 мес.) показывают отсутствие стенокардии и осложнений, связанных с использованием ПЖСА.

Выводы

- Первый опыт применения лапароскопически выделенной ПЖСА в качестве артериального кондуита для шунтирования коронарных артерий показал положительные результаты.

- Применение современной лапароскопической техники делает возможным безопасное и менее травматичное выделение ПЖСА.

- Применение лапароскопически выделенной ПЖСА в качестве аутоартериального кондуита для шунтирования коронарных артерий требует дальнейшего изучения.

\section{Список использованных источников References}

1. Taggart DP, Benedetto U, Gerry S, Altman DG, Gray AM, Lees B, et al. Bilateral versus Single InternalThoracic-Artery Grafts at 10 Years. N Engl J Med. 2019 Jan;380(5):437-46.
2. Akita S, Tajima K, Kato W, Tanaka K, Goto Y, Yamamoto R, et al. The long-term patency of a gastroepiploic artery bypass graft deployed in a semiskeletonized fashion: predictors of patency. Interact Cardiovasc Thorac Surg. 2019. PMID: 30649384. https://doi.org/10.1093/icvts/ivy346

3. Арутюнянян ВБ. Лучевая артерия как альтернативный кондуит в хирургическом лечении ИБС [диссертация]. Москва; 2009.

Arutyunyanyan VB. [Radial artery as an alternative conduit in the surgical treatment of coronary artery disease] [dissertation]. Moscow; 2009.

4. Bergsma TM, Grandjean JG, Voors AA, Boonstra PW, den Heyer P, Ebels T. Low recurrence of angina pectoris after coronary artery bypass graft surgery with bilateral internal thoracic and right gastroepiploic arteries. Circulation. 1998;97(24):2402-5.

5. Formica F, Ferro O, Greco P, Martino A, Gastaldi D, Paolini G. Long-term follow-up of total arterial myocardial revascularization using exclusively pedicle bilateral internal thoracic artery and right gastroepiploic artery. Eur J Cardiothorac Surg. 2004 Dec;26(6):1141-8.

6. Suma H. The Right Gastroepiploic Artery Graft for Coronary Artery Bypass Grafting: A 30-Year Experience. Korean J Thorac Cardiovasc Surg. 2016 Aug;49(4):22531. https://doi.org/10.5090/kjtcs.2016.49.4.225

\title{
The First Experience of Laparoscopic Gastroepiploic Artery Harvesting during Complete Autoarterial Myocardial Revascularization
}

\author{
Gabriyelyan A., Sidyuk A., Mazur A., Domanskyy T.. Beleiovych V., Beregovoy O., Mironyuk A., \\ Romanova S., Kudlai I., Havin I.. Savenko G.
}

Shalimov's National Institute of Surgery and Transplantation to National Academy of Medical Sciences of Ukraine, Kyiv, Ukraine

\section{Abstract}

The use of autoarterial grafts for myocardial revascularization is a priority for cardiac surgery. Laparoscopic right gastroepiploic artery (RGEA) harvesting may significantly reduce the risks of complications associated with laparotomy and expand the possibilities of its use as an autoarterial graft during coronary artery bypass grafting.

The aim. To represent the first experience of using the laparoscopically harvested RGEA as a graft for full autoarterial bypass surgery.

Materials and methods. Five coronary artery bypass surgeries using autoarterial grafts - two internal thoracic and one right gastroepiploic arteries - were performed on a beating heart. All the patients were males at the average age of $51 \pm 8$ had multifocal coronary artery damage. In all cases, RGEA was harvested laparoscopically.

Results. In the early postoperative period, patients did not have any cardiovascular events such as perioperative myocardial infarction, acute cerebrovascular accident, or arrhythmia. There were no gastrointestinal complications such as gastrostasis, stool disorders, vomiting. No significant differences were found between the indicators in patients who underwent complete autoarterial revascularization using RGEA and those who underwent surgery using the traditional method (LIMA-LAD, other arteries are bypassed by the veins).

Medium-term results of observation show the absence of angina pectoris and complications associated with the use of RGEA.

Conclusions. The first experience of using laparoscopically isolated RGEA as an arterial conduit for the coronary arteries bypassing showed positive results. The use of modern laparoscopic techniques allows for safer and less traumatic harvesting of RGEA.

Keywords: gastroepiploic artery, coronary artery bypass surgery, coronary artery disease. 


\title{
Перший досвід лапароскопічного виділення шлунково-сальникової артерії при повній аутоартеріальній реваскуляризації міокарда
}

\author{
Габрієлян А. В., Сидюк А. В., Мазур А. П., Доманський Т. М., Береговой О. В., Белейович В. В., \\ Миронюк О. І., Романова С. В., Кудлай І. В., Хавін І. Г., Савенко Г. Ю. \\ ДУ «Національний інститут хірургії і трансплантології ім. О. О. Шалімова НАМН України», м Київ, Україна
}

Резюме. Використання аутоартеріальних шунтів для реваскуляризації міокарда є пріоритетним напрямом кардіохірургії. Лапароскопічне виділення правої шлунково-сальникової артерії (ПШСА) дозволяє значно знизити ризики розвитку ускладнень, пов'язаних з лапаротомією, і розширити можливості її використання як аутоартеріальних кондуїтів при коронарному шунтуванні.

Мета. Продемонструвати перший досвід використання ПШСА, яка була лапароскопічно виділена, як шунта при повному аутоартеріальному шунтуванні.

Матеріали та методи. Виконано 5 операцій коронарного шунтування на працюючому серці з використанням аутоартеріальних шунтів - двох внутрішніх грудних і правої шлунково-сальникової артерій. Усі пацієнти були чоловіками, середній вік яких становив $51 \pm 8$ років, мали мультифокальне ураження коронарних артерій. У всіх випадках ПШСА була виділена лапароскопічно.

Результати. У ранній післяопераційний період у жодного пацієнта не було зафіксовано серцево-судинних патологій, таких як періопераційний інфаркт міокарда, гостре порушення мозкового кровообігу, а також порушень ритму. Ускладнень з боку шлунково-кишкового тракту у вигляді гастростазу, порушення випорожнень, блювання не відзначено. При порівнянні показників пацієнтів, яким виконували повну аутоартеріальну реваскуляризацію з використанням ПШСА, з даними пацієнтів, оперованих за традиційною методикою (LIMA-LAD, інші артерії шунтуються венами), достовірних відмінностей не виявлено.

Середньострокові результати спостереження демонструють відсутність стенокардії та ускладнень, пов'язаних з використанням ПШСА.

Висновки. Перший досвід застосування ПШСА, що була лапароскопічно виділена, як артеріального кондуїту для шунтування коронарних артерій показав позитивні результати. Застосування сучасної лапароскопічної техніки дає можливість провести безпечне та менш травматичне виділення ПШСА.

Ключові слова: сальникова артерія, коронарне шунтування, ішемічна хвороба серия.

Стаття надійшла в редакцію 22.03.2019 